\section{Comparison of Four Systems for Propagation of Coleus by Stem Cuttings}

\author{
Bryan J. Peterson ${ }^{1}$, Olivia Sanchez, Stephanie E. Burnett, \\ and Darren J. Hayes
}

ADDITIONAL INDEX WORDS. submist, fog, aeroponic, subirrigation, transplant, adventitious roots, overhead mist, fertilizer

Summary. Overhead mist (OM) facilitates the propagation of stem cuttings by preventing transpirational water loss. However, drawbacks to OM include the application of large volumes of water, potentially unsanitary conditions, irregular misting coverage, and leaching of foliar nutrients. We explored three alternatives to OM that might avoid these problems by applying moisture below, rather than overhead. These included 1 ) a submist (SM) aeroponic system configured to provide intermittent mist only to the rooting zone, 2) a subirrigation (SI) system that provided water via capillary action through perlite from a reservoir maintained below the base of each cutting, and 3) a subfog (SF) aeroponic system that was configured to provide constant fog only to the rooting zone. To initiate each system, we wetted perlite or filled reservoirs using either water or quarter-strength Hoagland solution. Stem cuttings of 'Wizard Mix' coleus (Plectranthus scutellarioides) were propagated in the systems for 21 days. Cuttings in the SM system produced more than three times as many roots as cuttings in the OM system, with roots more than six times the length. Root dry weights averaged $28 \mathrm{mg}$ for cuttings in the SM system, compared with only $3.5 \mathrm{mg}$ among cuttings receiving OM. The SF and SI systems produced results broadly comparable to the OM. Fertilizer did not consistently improve rooting measures across the systems. Although we observed few fine roots on cuttings rooted using SM, they transplanted well into a soilless substrate and quickly produced new root growth. The SM system used less than $1 / 5$ the water used by the SI system, and less than $1 / 50$ the water used by the SF system. In comparison, a single OM nozzle operating for 10 seconds released about onethird of the total water lost through transpiration from each SM system over the entire experiment. Our results show that SM systems merit further evaluation for propagation of plants by stem cuttings.

$\mathrm{O}$ verhead mist revolutionized the propagation industry by providing reliable means to manage transpirational water losses by leafy stem cuttings. This system slows transpiration of cuttings primarily by decreasing leaf temperatures through evaporative cooling from the leaf surface (Hartmann et al., 2011). However, OM has potential drawbacks, including the use of large volumes of

School of Food and Agriculture, University of Maine, 5722 Deering Hall, Orono, ME 04469-5722

Maine Agricultural and Forest Experiment Station Publication Number 3572. We thank the Maine Food and Agriculture Center for providing funding through a Horticulture Research Grant. This project was supported by the U.S. Department of Agriculture, $\mathrm{Na}$ tional Institute of Food and Agriculture, Hatch project numbers \#ME021423 and \#ME021614, and \#ME0-31401 through the Maine Agricultural \& Forest Experiment Station.

We thank SunGro for providing growing media. Thank you to Bradly Libby for technical support. We also thank Gregory Melcher, Andrew Chase, and Mike Munson for helpful assistance.

${ }^{1}$ Corresponding author. E-mail: bryan.j.peterson@ maine.edu.

https://doi.org/10.21273/HORTTECH03926-17 water, potentially unsanitary conditions created by persistent water films on leaves (Preece, 2003), the potential for anaerobic conditions in the rooting zone, the depression of root-zone temperatures by evaporative cooling (Hartmann et al., 2011), nonuniform misting coverage, leaching of foliar nutrients (Preece, 2003), difficulty controlling cutting nutrition during propagation (Hartmann et al., 2011; Zhang and Graves, 1995), and the need to extensively acclimate cuttings to a low-humidity, mist-free environment.

Several authors have considered alternatives to $\mathrm{OM}$ for propagation of plants by stem cuttings, which we refer to here as SI, SM, and SF (Zhang and Graves, 1995). Graves and Zhang (1996) evaluated the suitability of SI for the propagation of several woody and herbaceous plant species, and found that such a system can be an effective alternative to OM. Moreover, Zhang and Graves (1995) found rooting could be improved in SI when a fertilizer solution was used instead of water. Another alternative system that merits investigation relies on the application of mist from below the cutting, to the base of the stem inserted into an enclosed chamber. Several such aeroponic systems are available on the market for use by home gardeners, but do not seem to be marketed for commercial propagation. Several authors have evaluated SM aeroponic systems for propagation of plants by stem cuttings, with promising results (Mehandru et al., 2014). Another aeroponic product on the market (Cyclone Ultrasonic Fogger; FutureGarden, Lindenhurst, NY) can be used to supply a fog of nebulized water or fertilizer solution to the bases of cuttings inserted into a rooting chamber. To our knowledge, the potential efficacy of this system for propagation has not been formally evaluated in the academic literature.

We speculated that each of these systems might offer several of the following advantages to $\mathrm{OM}$ for the propagation of plants by leafy stem cuttings. These include limited water usage, increased sanitation and reduced foliar disease pressures, superior oxygenation to the rooting zone, maintenance of high rootzone temperatures in the absence of evaporative cooling, uniform application of water to each cutting, no leaching of nutrients, efficient delivery of water-soluble fertilizer during propagation, and a reduction in acclimation requirements typical of cuttings accustomed to receiving foliar mist. Moreover, in two of the

\begin{tabular}{llll}
\hline $\begin{array}{l}\text { Unit } \\
\text { To convert U.S. to SI, } \\
\text { multiply by }\end{array}$ & U.S. unit & SI unit & $\begin{array}{l}\text { To convert SI to U.S., } \\
\text { multiply by }\end{array}$ \\
\hline 3.7854 & gal & $\mathrm{L}$ & 0.2642 \\
2.54 & inch $(\mathrm{es})$ & $\mathrm{cm}$ & 0.3937 \\
28.3495 & $\mathrm{Oz}$ & $\mathrm{g}$ & 0.0353 \\
28,350 & $\mathrm{oz}$ & $\mathrm{mg}$ & $3.5274 \times 10^{-5}$ \\
1 & $\mathrm{ppm}$ & $\mathrm{mg} \cdot \mathrm{L}^{-1}$ & 1 \\
$\left({ }^{\circ} \mathrm{F}-32\right) \div 1.8$ & ${ }^{\circ} \mathrm{F}$ & ${ }^{\circ} \mathrm{C}$ & $\left({ }^{\circ} \mathrm{C} \times 1.8\right)+32$
\end{tabular}


systems (SM and SF), root development could be assessed in situ without disturbing fragile, developing roots. Our aim here was to conduct a proof-of-concept evaluation to explore the general merits of each system.

The primary objective of this study was to compare rooting and posttransplant performance of coleus propagated in four propagation systems: traditional OM, SM aeroponic, SF aeroponic, and a modified SI system. The second objective was to determine whether the addition of water-soluble fertilizer was beneficial in any of these systems.

\section{Materials and methods}

We built four propagation systems: traditional OM, aeroponic SM, aeroponic SF, and SI. The traditional OM system consisted of a single lowpressure nozzle (Vibro-Spreader; RainTal, Or-kiva, Israel) mounted on the top of a 22 -inch-tall polyvinyl chloride (PVC) riser. Mist was turned on for $10 \mathrm{~s}$ every 10 min using a normally closed 24-VAC solenoid valve (Netafim, Fresno, CA) connected to an electronic timer (Gemini 6A; Phytotronics, Earth City, MO). Cuttings grown in this system were inserted basally into open trays $(40 \times 40 \times 13 \mathrm{~cm})$ containing coarse perlite (Whittemore Co., Lawrence, MA) initially wetted with tap water or fertilizer solution.

The SI system was a modified version of the system Graves and Zhang (1996) described. In this system, 32 L of coarse perlite was placed in water-tight black PVC tubs $(64 \times$ $45 \times 14 \mathrm{~cm}$ ) leveled on greenhouse benches. Water or fertilizer solution was filled to a depth of 2.5 inches to ensure that the basal end of each cutting was $\approx \mathrm{l}$ inch above the water or solution. During the experiment, additional water was added every $1-2 \mathrm{~d}$ as needed to maintain water or fertilizer solution to the initial volume of $\approx 16 \mathrm{~L}$.

The SM system consisted of 16 mist nozzles (Botanicare $330^{\circ}$ Micro Sprayer; American Agritech, Chandler, AZ) tapped into a 3/4-inch PVC manifold with dimensions of $56 \times 33 \mathrm{~cm}$ within a 27 -gal plastic tub with dimensions of $74 \times 52 \times 37$ $\mathrm{cm}$ (Commander Black Tote; Centrex Plastics, Findlay, $\mathrm{OH}$ ). Hooked to the manifold was a submersible pump (Eco-plus ECO-396; Sunlight Supply,
Vancouver, WA) connected to a timer (Titan Controls Apollo 12 Timer; Sunlight Supply), which operated the pump for $10 \mathrm{~s}$ every $10 \mathrm{~min}$. Holes of $3 / 8$ inch diameter were drilled in the lid of the tub to insert the cuttings, and a $1 / 2$-inch-thick sheet of rigid foam insulation with $1 / 4$-inch holes was placed over the lid to secure cuttings in place. The level of water was checked daily; more water was added as needed to maintain a uniform volume $(32 \mathrm{~L})$ throughout the experiment.

The SF system was constructed using a commercially available fog generator that nebulizes water by vibrating ceramic discs (Cyclone Ultrasonic Fogger). A large black plastic tub identical to those used for the SM systems served as a reservoir for water or fertilizer solution, and a shop vacuum hose connected the fog outlet of the ultrasonic fogger to the headspace in the tub, which doubled as the rooting chamber. The lid of each tub was modified in the same way as those used on the SM systems. Each SF aeroponic system, which operated continuously, was checked daily and the large reservoir was refilled with water as needed to maintain the $32-\mathrm{L}$ volume initially filled with water or fertilizer solution.

Three replications of each system were operated using tap water alone, whereas three additional replications of each system were initiated with a liquid fertilizer solution of quarterstrength modified Hoagland solution, which provided $\approx 52 \mathrm{mg} \cdot \mathrm{L}^{-1}$ nitrogen initially to each system (Hoagland and Arnon, 1950). For the latter replications, we applied fertilizer at the start of the experiment to fill tubs (SM and SF systems) or saturate perlite (OM and SI systems). Thereafter, we replenished the lost fertilizer solution from each system with tap water. Our goal was to evaluate whether initially increasing fertility of the rooting zone would improve the rooting of stem cuttings.

On 29 Jan. 2016, cuttings that were $\approx 12 \mathrm{~cm}$ long were taken from stock plants of 'Wizard Mix' coleus, grown from seed (Fedco Seeds, Waterville, ME). Because the cultivar was a mix, we collected cuttings from plants of five cultivars (Maroon, Coral Sunrise, Scarlet, Jade, and Velvet Red) with two cuttings of each cultivar placed in each replicate system.
On 19 Feb. 2016, root rating (from $0=$ no roots to $5=$ superior rooting) and length of the longest root were recorded from every cutting. Half of the cuttings (one of each cultivar) were destructively harvested, the total number of roots was counted, and the roots and shoots were dried in a room maintained at $\approx 68{ }^{\circ} \mathrm{C}$ for $\mathrm{l}$ week to measure root and shoot dry weights and root:shoot. On the same day, the other half of the cuttings were transplanted into 5 -inch azalea pots (Kord, Toronto, ON, Canada) containing a commercial peat-based growing medium (Fafard 1-PV; Sun Gro Horticulture, Agawam, MA). After transplant, plants were handwatered as needed, and on 2 Mar. 2016, they were top-dressed with $5 \mathrm{~g}$ of $14 \mathrm{~N}-4.2 \mathrm{P}-11$.6K controlled-release fertilizer (Osmocote; Everris, Dublin, $\mathrm{OH})$. On 1 Apr. 2016, we measured the plant height from the surface of the medium to the tallest point on the plant, and harvested and dried each plant in a drying room, to record shoot and root dry weights and root:shoot.

The cuttings and container plants were grown in a Quonset greenhouse covered with a triple layer polycarbonate glazing. During propagation, cuttings were shaded with $50 \%$ Mylar shadecloth. When plants were grown in containers, they were not shaded. The average daily temperature from 19 Feb. until 24 Mar. 2016, measured using a weather station (WatchDog 1650 Micro Station; Spectrum Technologies, Aurora, IL), was $21.7^{\circ} \mathrm{C}$. Photosynthetically active radiation was measured using a quantum light sensor attached to the same weather station; daily light integral (DLI) was calculated from this data by multiplying $\mu \mathrm{mol} \cdot \mathrm{m}^{-2} \cdot \mathrm{s}^{-1}$ by $1,000,000$ and dividing this number by 86,400 to obtain $\mathrm{mol} \cdot \mathrm{m}^{-2} \cdot \mathrm{d}^{-1}$. DLI averaged $10.19 \mathrm{~mol} \cdot \mathrm{m}^{-2} \cdot \mathrm{d}^{-1}$.

The study was analyzed as a splitplot experiment with propagation system on the level of the main plot, fertilizer treatment on the level of the split plot, and three blocks that each contained one replication of each system and fertilizer combination. During the study, there was no evidence that response variables differed by cultivar; measurements from all cuttings (subsamples) within each replication system were simply averaged before data analysis. For each system and fertilizer combination, 5 or 10 
subsamples constituted the average, depending on the variable (detailed above). Analysis of variance was used in the agricolae package for $\mathrm{R}$ (version 0.98.1103; RStudio, Boston, MA) to test for the main effects of system, and Fisher's least significant difference was used for means separation among those systems operated without fertilizer. Next, $t$ tests using pooled variances tested for an effect of fertilizer by comparing each system initiated with fertilizer solution to the baseline responses obtained using water alone.

\section{Results}

All four systems maintained the turgor of the cuttings for the duration of the experiment. Cuttings in the SF system, in which modest wilting was observed for the first couple days, recovered and did not wilt again. Cuttings from all four systems produced roots, with those produced in SI and OM systems somewhat thicker and with more evident fine roots than those produced in the SM and SF systems (Fig. 1).

In the comparison of systems operated with water alone, coleus cuttings in SM outperformed those in the other systems for all four measures of rooting (Table 1). Cuttings in SM had roots more than seven times the length of those in the OM treatment, and root ratings and root numbers were about four times as great. Finally, the root dry weights of cuttings rooted in the SM system were $\approx 15$ times that of the cuttings propagated with OM (Table 1). Plants rooted in SI had root lengths and subjective root ratings greater than those produced by OM and SF. The SF system produced rooting values on cuttings that were similar to those receiving OM (Table 1 ).

Cuttings from all four systems transplanted readily to a peat-based greenhouse medium. However, those cuttings rooted in SM established and grew more rapidly, producing plants that were both taller and with greater root dry weights than plants propagated with OM (Table 2). Plants originating in SM also produced greater shoot dry weights than plants from the three other systems.

The use of water-soluble fertilizer had limited influence on root development of cuttings during propagation, regardless of system (Table 1 ). However, we did record a fertilizer effect in the SM system after transplant into a peat-based medium. Cuttings that were rooted in the SM system with fertilizer subsequently developed into taller plants with more than twice the root dry weight, and nearly twice the shoot dry weight, of cuttings rooted in SM with water (Table 2).

\section{Discussion}

To our knowledge, this is the first study to compare the efficacy of

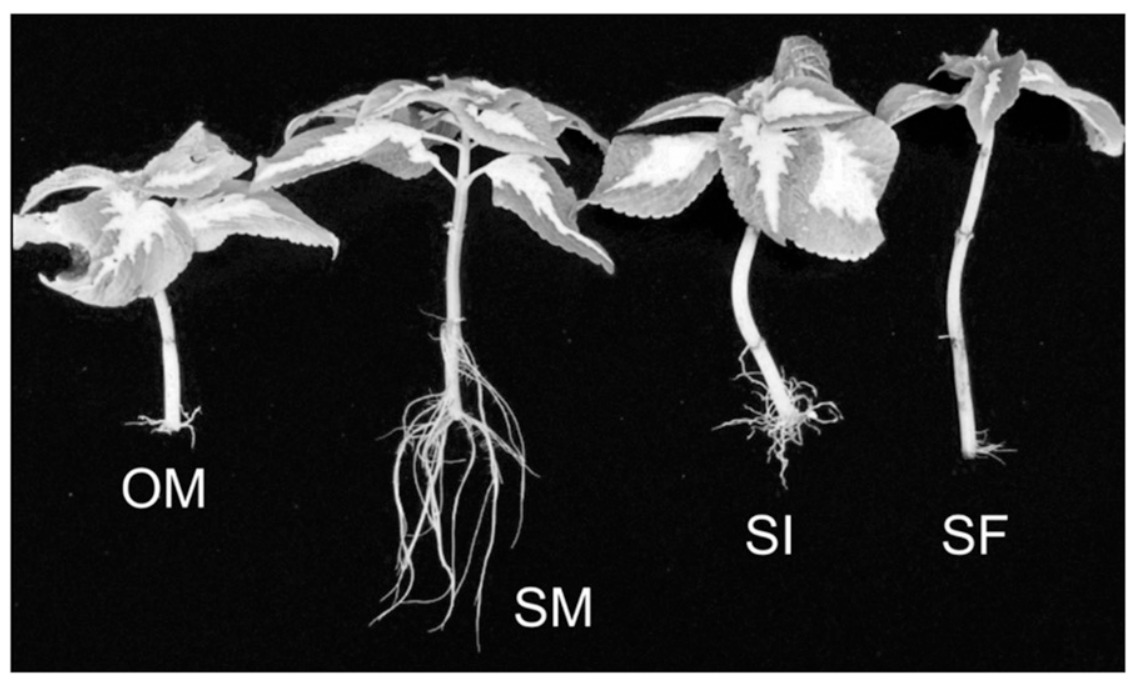

Fig. 1. Representative cuttings of coleus after 3 weeks in each of the four propagation systems: overhead mist (OM), submist (SM), subirrigation (SI), and subfog (SF). Cuttings in the SM systems produced longer, thinner roots than cuttings in the other systems, and typically produced roots more uniformly around the stem and higher up the stem. these four propagation systems simultaneously, and to assess the benefit of fertilizer solution on adventitious rooting of cuttings in each. Our results illustrate how SM may be an effective alternative to $\mathrm{OM}$ for the propagation of herbaceous crops by stem cuttings. Cuttings of coleus in SM produced root systems of greater weight, with longer and more numerous roots, than cuttings in the three other systems (Table 1). Moreover, cuttings from SM transplanted readily and continued to develop robust root systems in a soilless medium (Table 2 ), with root tips reaching the wall of the container within l week. Previous authors have successfully propagated plants including winged yam (Dioscorea alata), white yam (Dioscorea rotundata), paimpa (Caralluma edulis), jeewanti (Leptadenia reticulata), and dambel (Tylophora indica) in SM or aeroponic systems without $\mathrm{OM}$ (Maroya et al., 2014; Mehandru et al., 2014). In comparison with propagation using OM, our results with SM seem to agree with those of Soffer and Burger (1989), who demonstrated that an aerohydroponic system produced measures of rooting in chrysanthemum (Chrysanthemum $\times$ morifolium) and weeping fig (Ficus benjamina) stem cuttings that were superior to those obtained by using OM.

Subirrigation is also a viable method for propagating coleus in the absence of OM, performing intermediately to SM and OM in measures of rooting. Our results agree with those of Zhang and Graves (1995), who found that coleus and 'Charm' chrysanthemum propagated in a SI system were similar to those propagated in an OM system (Zhang and Graves, 1995). However, 'Frank's Red' red maple (Acer rubrum) propagated in SI had greater root dry weight than cuttings propagated by using OM (Zhang and Graves, 1995). The least promising alternative to OM was the SF system, which produced measures of rooting comparable with OM in our study (Table 1 ). Subfog does not seem like a practical approach for commercial propagation, as the water in this system had to be refilled almost daily, a process that could be readily automated but that nonetheless uses large volumes of water.

Root ratings were higher when coleus was propagated in SM compared 
Table 1. Average root length, root rating, root number, and root dry weight among cuttings of coleus after $21 \mathrm{~d}$ in one of four propagation systems.

\begin{tabular}{|c|c|c|c|c|}
\hline System $^{z}$ & Root length $(\mathrm{cm})^{\mathrm{y}}$ & Root rating $(0-5 \text { scale })^{x}$ & Roots (no.) & Root dry wt (mg) \\
\hline Overhead mist (OM) & $1.3 \mathrm{c}$ & $0.8 \mathrm{c}$ & $11.1 \mathrm{~b}$ & $1.9 \mathrm{~b}$ \\
\hline Subfog $(\mathrm{SF})$ & $1.3 \mathrm{c}$ & $0.7 \mathrm{c}$ & $11.1 \mathrm{~b}$ & $1.3 \mathrm{~b}$ \\
\hline Submist (SM) & $9.9 \mathrm{a}$ & $3.3 \mathrm{a}$ & $43.2 \mathrm{a}$ & $28.7 \mathrm{a}$ \\
\hline \multicolumn{5}{|l|}{ Fertilizer effect ${ }^{\mathrm{v}}$} \\
\hline $\mathrm{OM}$ & $+0.7 \mathrm{NS}$ & $+0.3 \mathrm{NS}$ & $+4.3 \mathrm{NS}$ & $+0.6 \mathrm{NS}$ \\
\hline SM & $+1.1 \mathrm{NS}$ & $+0.5 \mathrm{NS}$ & $+12.5 \mathrm{NS}$ & $-1.4 \mathrm{NS}$ \\
\hline
\end{tabular}

${ }^{\mathrm{z}}$ System section depicts means for each system during propagation without fertilizer; means within each column followed by the same letter are not significantly different at $\alpha=0.05$. Data were analyzed using analysis of variance and Fisher's least significant difference in the agricolae package in R (RStudio).

${ }^{\mathrm{y}}$ Length of the longest root; $1 \mathrm{~cm}=0.3937$ inch.

${ }^{\mathrm{x}} 0=$ no roots, $5=$ superior rooting with roots uniformly distributed around the stem.

${ }^{\mathrm{w}} 1 \mathrm{mg}=3.5274 \times 10^{-5} \mathrm{oz}$.

${ }^{v}$ Fertilizer effect section depicts mean difference in rooting measurements when systems were initiated with quarter-strength Hoagland's solution instead of water; NS = nonsignificant and * = significant at $\alpha=0.05$. Data were analyzed using $t$ tests in the agricolae package in $\mathrm{R}$.

Table 2. Average measures of growth among cuttings of coleus transplanted from one of the four propagation systems into a greenhouse medium and grown for $34 \mathrm{~d}$ with a slow-release fertilizer applied.

\begin{tabular}{|c|c|c|c|c|}
\hline System $^{z}$ & Plant ht $(\mathrm{cm})^{\mathrm{y}}$ & Root dry wt (mg) & Shoot dry wt (mg) & Root:shoot (ratio) \\
\hline Overhead mist (OM) & $11.1 \mathrm{~b}$ & $154.8 \mathrm{~b}$ & $902.3 \mathrm{~b}$ & $0.18 \mathrm{a}$ \\
\hline Subfog $(\mathrm{SF})$ & $11.0 \mathrm{~b}$ & $211.0 \mathrm{ab}$ & $1,029 \mathrm{~b}$ & $0.20 \mathrm{a}$ \\
\hline Subirrigation (SI) & $11.6 \mathrm{ab}$ & $251.0 \mathrm{a}$ & $1,062 \mathrm{~b}$ & $0.23 \mathrm{a}$ \\
\hline Submist (SM) & $13.1 \mathrm{a}$ & $252.0 \mathrm{a}$ & $1,290 \mathrm{a}$ & $0.19 \mathrm{a}$ \\
\hline \multicolumn{5}{|l|}{ Fertilizer effect ${ }^{\mathrm{x}}$} \\
\hline $\mathrm{OM}$ & $0.0 \mathrm{NS}$ & $+34.3 \mathrm{NS}$ & $+173.0 \mathrm{NS}$ & $0.0 \mathrm{NS}$ \\
\hline SM & $+2.0 *$ & $+286.0 *$ & $+1,084.4^{*}$ & $0.0 \mathrm{NS}$ \\
\hline
\end{tabular}

${ }^{\mathrm{z}}$ System section depicts mean outcomes of plants that did not receive fertilizer during the propagation period; means within each column followed by the same letter are not significantly different at $\alpha=0.05$. Data were analyzed using analysis of variance and Fisher's least significant difference in the agricolae package in R (RStudio).

${ }^{\mathrm{y}} 1 \mathrm{~cm}=0.3937$ inch, $1 \mathrm{mg}=3.5274 \times 10^{-5} \mathrm{oz}$

${ }^{x}$ Fertilizer effect section depicts mean difference for measures of growth by plants propagated in systems that were initiated with quarter-strength Hoagland's solution instead of water; NS $=$ not significant and ${ }^{*}=$ significant at $\alpha=0.05$. Mean separation was performed using $t$ tests in the agricolae package in $\mathrm{R}$.

with all other systems (Table 1). Subirrigation systems produced plants that had higher root quality compared with fog and OM but that were still inferior to plants propagated in SM (Table 1). Root quality of many herbaceous plants, including 'Stained Glass' coleus is influenced by factors that include the season when cuttings are harvested (Crawford et al., 2016). Our results demonstrate that the type of propagation system also impacts quality of the root system.

Initiating the systems with a fertilizer solution was not important for the production of well-rooted cuttings in this study, as differences in rooting between fertilized and unfertilized cuttings were minimal in all systems (Table 1). Although fertilizer increases shoot growth of herbaceous cuttings during propagation under OM (Currey and Lopez, 2014), the importance of fertilizer in root development during propagation is less clear. Applied fertilizer may increase, decrease, or have no effect on root dry weight of herbaceous stem cuttings during propagation (Currey and Lopez, 2014; Santos et al., 2009). As we only applied fertilizer once at the beginning of the propagation cycle, we expected that differences in rooting between fertilizer treatments were most likely for those systems that retained the fertilizer solution over the course of the study. Liquid fertilizer was probably lost most rapidly in the SF systems when the initial solution was nebulized and discharged from the system. Likewise, any solution used to initiate the $\mathrm{OM}$ system was probably leached if it was not quickly taken up by cuttings. Surprisingly, although SM and SI systems retained the applied fertilizer solution, consequential differences in rooting were not observed between these fertilized and unfertilized systems (Table 1). We are interested in further exploring the differences in fertilizer applied during a sustained period in the future. However, it would be challenging to adequately compare fertility in SM and OM systems, since water-soluble fertilizer leaches out of substrates in OM but is retained in the SM reservoir, and slow-release fertilizer is unsuitable for use in a SM system.

Although fertilizer solutions did not obviously impact root formation during propagation, a delayed but dramatic benefit of fertilizer during SM propagation manifested after establishment in a greenhouse medium. Submist cuttings propagated using fertilizer solution subsequently grew $15 \%$ taller, with $113 \%$ more root weight and $85 \%$ more shoot weight (Table 2), than cuttings propagated 
without fertilizer, despite the uniform application of slow-release fertilizer to all plants following transplantation. Therefore, it is important to consider not only the effect that fertilizer might have on root development during propagation, but also its potential "priming effect" on subsequent growth in containers.

We encountered challenges in the implementation of several of these systems. For example, in the construction of the SI system, we needed to carefully level the tub acting as a reservoir, and the perlite within it, so that all cuttings were the same height from the saturated zone. In the implementation of the SM and SF systems, securing cuttings through the lid of the chamber in a removable manner was a challenge. At the end of the experiment, some holes in the lid had to be manually enlarged with a razor blade to permit the removal of rooted cuttings. Some growers and hobbyists use foam pucks inserted into larger holes, an approach that seems too expensive and time- and labor-intensive for commercial propagation. We are exploring alternative methods to secure cuttings in these systems in such a way as to make insertion and removal of cuttings rapid, without a high cost per cutting.

Most of the problems we encountered were with the SF system, which required substantial troubleshooting to operate effectively. The cost of the fog generators we used made these the most expensive systems to implement. The generators themselves were susceptible to malfunctioning if their ceramic nebulizer discs were not installed at the proper depth relative to the water level in the system, which happened initially because of shifting of these units within the fog generator during shipping. Therefore, we had to disassemble the generators to correct the orientation of these units before they would function correctly. Next, the placement of the hose connecting the fog output to the headspace of the tub was critical; if any portion of the hose settled lower than both ends, condensation pooling in the hose soon blocked the flow of fog to the chamber. Finally, we needed to construct the system with a degree of "leakiness" because an airtight rooting chamber would render the fan in the fog generator ineffective at delivering fog to the chamber. The holes into which cuttings were inserted were somewhat wider than the cuttings, allowing fog to freely escape the system and prevent a buildup of pressure.

One potential advantage we observed in the use of SM for propagation instead of traditional OM is that SM systems lose water only through transpiration through the cuttings instead of directly to the atmosphere by evaporation during misting and from surfaces in the greenhouse. Although we did not measure the amount of water the OM system used over the duration of the study, we noted the amount of water we added to the SM systems. Each SM system, which only lost water because of cutting transpiration, used the same amount of water during the entire study as a single OM nozzle operating for $30 \mathrm{~s}$. This observation justifies scaling up the system for direct comparisons of water use during propagation on a commercial scale.

Our next goals are to extend the present research to additional herbaceous and woody plant species to answer questions related to the implementation and efficacy of SM systems, to explore the biology underlying the positive results of cuttings propagated in SM systems, and explore the potential for SM systems in the propagation of difficult-toroot plants. One particularly important challenge of such a system for greenhouse crops might be the fact that cuttings are not rooted into plugs of solid media, which may make transplanting more time consuming or change current transplanting systems. This concern seems less problematic for nursery crops, which are often bare-rooted after propagation to be overwintered in cold storage.

\section{Conclusions}

This research has the potential to result in profitability for the green industry because propagation is a major component of horticulture crop production. The Census of Horticulture Specialties (U.S. Department of Agriculture, 2016) indicated that propagation alone was valued at $\$ 695$ million in 2014. This research may contribute substantially to improvement in propagation technology. By eliminating many of the shortcomings of OM, SM could set a new standard for plant propagation technology and broaden the range of plants that can be propagated from stem cuttings. In this study, cuttings in SI and SF systems produced rooting comparable to those in OM, whereas cuttings rooted in the SM aeroponic systems produced dramatically more roots, longer roots, and root systems of greater dry weight than cuttings in the OM systems. Cuttings rooted in SM transplanted effectively and grew rapidly in containers of solid media. Finally, despite not affecting root development during propagation, the use of fertilizer solution in SM propagation systems seemed to prime cuttings for increased growth once transplanted into a solid medium.

\section{Literature cited}

Crawford, B.D., J.M. Dole, and B.A. Bergman. 2016. Influences of season and cutting week within a propagation cycle on rooting of 'Stained Glass' coleus shoot tip cuttings are not overcome by rooting compound treatment. HortTechnology 26:620-627.

Currey, C. and R. Lopez. 2014. Controlledrelease fertilizer during cutting propagation affects growth and tissue nutrient concentrations of rooted cuttings of annual bedding plants. HortScience 49:152-159.

Graves, W.R. and H. Zhang. 1996. Relative water content and rooting of subirrigated stem cuttings in four environments without mist. HortScience 31:866-868.

Hartmann, H.T., D.E. Kester, F.T. Davies, and R.L. Geneve. 2011. Hartmann and Kester's plant propagation: Principles and practices. 8th ed. Prentice Hall, Upper Saddle River, NJ.

Hoagland, D.R. and D.I. Arnon. 1950. The water-culture method for growing plants without soil. California Agr. Expt. Sta. Circ. 327 (revised).

Maroya, N., M. Balogun, R. Asiedu, B. Aighewi, P. Lava Kuma, and J. Augusto. 2014. Yam propagation using 'aeroponics' technology. Annu. Res. Rev. Biol. 4:3894-3903.

Mehandru, P., N.S. Shekhawat, M.K. Rai, V. Kataria, and H.S. Gehlot. 2014. Evaluation of aeroponics for clonal propagation of Caralluma edulis, Leptadenia reticulata, and Tylophora indica - Three threatened medicinal Asclepiads. Physiol. Mol. Biol. Plants 20:365-373. 


\section{Research Reports}

Preece, J.E. 2003. A century of progress with vegetative plant propagation. HortScience 38:1015-1025.

Santos, K.M., P.R. Fisher, and W.R. Argo. 2009. Stem versus foliar uptake during propagation of Petunia $\times$ bybrida vegetative cuttings. HortScience 44:1974-1977.
Soffer, H. and D.W. Burger. 1989. Plantpropagation using an aero-hydroponics system. HortScience 24:154.

U.S. Department of Agriculture. 2016. 2014 census of horticultural specialties. 27 May 2016. <https://www.
agcensus.usda.gov/Publications/2012/ Online_Resources/Census_of Horticulture_Specialties $/>$.

Zhang, H. and W.R. Graves. 1995. Subirrigation to root stem cuttings: Comparison to intermittent mist and influence of fertilization. HortTechnology 5:265-268. 